\title{
BMJ Open Prevalence of bullying in the nursing workplace and determinant factors: a nationwide cross-sectional Polish study survey
}

\author{
Lena Izabela Serafin (1D , Bożena Czarkowska-Pączek
}

To cite: Serafin LI, Czarkowska-Pączek B. Prevalence of bullying in the nursing workplace and determinant factors: a nationwide cross-sectional Polish study survey. BMJ Open 2019;9:e033819. doi:10.1136/ bmjopen-2019-033819

- Prepublication history for this paper is available online. To view these files, please visit the journal online (http://dx.doi. org/10.1136/bmjopen-2019033819).

Received 23 August 2019 Revised 11 November 2019 Accepted 12 November 2019

\section{ABSTRACT \\ Objectives In the present study, we aimed to investigate the prevalence of bullying among Polish nurses, and to identify the most common negative acts, as well as individual and work-related risk factors for workplace bullying. \\ Methods Cross-sectional study designed using an online survey. The total study sample was 404 nurses, each having over 6 months of working experience. Data were collected using the Polish version of the Negative Act Questionnaire-Revised. Linear stepwise regression analysis and logistic regression analysis were performed to assess predictors of greater reporting of perceived workplace bullying}

Results Bullying was experienced by $65.84 \%$ of participants. Perceived workplace bullying was associated with sex $(p=0.043)$, age $(p=0.003)$, seniority $(p=0.006)$, number of working hours per week $(p=0.010)$ and position $(p=0.029)$. Logistic regression analysis with the dependent variable of bullying according to Leymann's rigorous criteria revealed that the model could include four variables: age from 50 to 59 , seniority of 11-15 years, $>45$ working hours per week and a bachelor's degree in nursing.

Conclusions An alarming percentage of nurses were victims of bullying. Among all variables included in the regression model, the most significant predictors of perceived workplace bullying were age, seniority, work overtime and bachelor's degree education. Bullying prevention and improvement of well-being at work must be addressed as part of an overall strategy to deal with turnover.

\section{INTRODUCTION}

(C) Author(s) (or their employer(s)) 2019. Re-use permitted under CC BY-NC. No commercial re-use. See rights and permissions. Published by BMJ.

Department of Clinical Nursing Medical University of Warsaw, Warszawa, Poland

Correspondence to Dr Lena Izabela Serafin; lena.serafin@wum.edu.pl
Nurse retention is currently considered a critical issue by the largest nursing organisations worldwide. ${ }^{12}$ The WHO estimates that the global needs-based shortage of nurses and midwives will be over 9 million by $2030 .{ }^{3} \mathrm{An}$ unhealthy work environment, including workplace bullying, has been reported as a reason that nurses leave the profession. ${ }^{3-6}$ Workplace bullying was first identified in the 1980s by the Swedish researcher Leymann, who defined it as an ongoing conflict in which the victim is

\section{Strengths and limitations of this study}

- Our investigation revealed that higher risk of workplace bullying is associated with young age, fewer years of nursing experience, position, educational level and working overtime.

- Our study showed the need to monitor nursing work environments, especially mid-level management, therefore managers who play crucial roles in bullying issue should be supervised and externally supported.

- This study was quantitative and cross-sectional, and designed to assess negative acts in the nursing workplace within a given time frame and such behaviours may change over time and differ among workplaces, limiting the generalisability of this study's findings to other times and places.

subjected to one or more negative acts weekly over a period of at least 6 months. ${ }^{7}$ Einarsen et al defined workplace bullying as persistent exposure to interpersonal aggression and mistreatment from colleagues, superiors, or subordinates. ${ }^{8}$ The prevalence of bullying in the workplace can be assessed using either a self-labelling approach or survey with defined criteria. ${ }^{9}$ Workplace bullying can be psychological and/or physical in nature, with data indicating that it is primarily psychological, based on both perceived and actual psychological harm. ${ }^{10}$

Bullying is strongly correlated with intention to leave the profession, ${ }^{11-15}$ and contributes to absenteeism and intention to leave the organisation. ${ }^{16}$ Sauer and McCoy demonstrated that bullying decreases quality of life and impedes ability to deliver effective and safe patient care. ${ }^{17}$ Therefore, bullying could lead to negative patient outcomes, such as falls and medical errors. ${ }^{18} 19$ Furthermore, bullying has detrimental effects on individuals, with potential consequences including depression and anxiety, physical symptoms 
such as palpitations, headaches and fatigue as well psychoemotional issues. ${ }^{20}{ }^{21}$ Prolonged exposure to bullying in a work environment can lead to post-traumatic stress disorder symptoms, work dysfunction and substance abuse. $^{21} 22$

Bullying in nursing workplaces has been widely studied, and the results indicate that this phenomenon is influenced by sex, ${ }^{23}$ age, ${ }^{2324}$ seniority, ${ }^{162324}$ and education/ qualification level. ${ }^{1625}$ Studies have also reported that unit specification plays a role. ${ }^{232627}$ Nurses indicate that their main bullying sources are their managers/supervisor ${ }^{613} 23$ or nursing peers. ${ }^{28}$ In addition, this phenomenon is influenced by cultural factors and world region, ${ }^{29}{ }^{30}$ which is why to create optimal intervention in bullying, studies must be conducted across countries. ${ }^{16}$

Overall, studies of workplace bullying show that this problem depends on many variables. Furthermore, the phenomenon itself varies over time, and thus must be continuously investigated. In the present study, we aimed to investigate the prevalence of bullying among Polish nurses, and to identify the most common negative acts, as well as individual and work-related risk factors for workplace bullying.

\section{MATERIALS AND METHODS \\ Study design}

We performed a cross-sectional study, in which an online survey was used to collect data between September and December 2018. A link to the survey was available on the webpage of the Warsaw District Chamber of Nurses and Midwives, and was shared using social media, including specialised Facebook groups. This recruitment method was intended to avoid employer-biassed responses, which might have occurred if nurses were recruited through their employers.

\section{Ethical consideration}

Each participant received a cover letter explaining the study purpose and terms of participation and ensuring confidentiality. The responders' names were not recorded on the questionnaire, thus rendering the data anonymous. Informed consent was indicated by voluntary participation in the survey. Sending the completed questionnaire was synonymous with consent to participate in the study.

\section{Sample}

The population of interest for this study was nurses working in Polish healthcare facilities, who had at least 6 months of working experience. Nurses with less than 6 months of experience were excluded because the bullying questionnaire that was used in the present study asked about past 6 months experience. Based on thumb principle for sample size estimation (30 subjects for each study variable) $)^{31}$; 404 participants were included in the final analyses. The link to the questionnaire was opened
1002 times, while 411 of respondents sent completed survey.

\section{Patient and public involvement}

This research was done without patient and public involvement. Patients/participated nurses were not invited to comment on the study design and were not consulted to develop relevant outcomes or interpret the results. They were not invited to contribute to the writing or editing of this document for readability or accuracy.

\section{Variables and instrument}

For this study, we used the Polish version of the standard self-report measure Negative Acts Questionnaire-Revised (NAQ-R). This scale was originally developed by Einarsen et al based on their definition of workplace bullying and is widely used to measure workplace bullying in many professions. ${ }^{32}$ Participants were asked about their experience at work during the last 6 months. Respondents who experienced one or more negative acts, at least weekly, over a period of 6 months were classified as targets of bullying according to Leymann's criteria for bullying assessment. ${ }^{7}$ Einarsen et al recommended that bullying be defined by two negative acts committed weekly during the last 6 months, and this assessment is herein referred to as Leyman's rigorous criteria or operational bullying definition. $^{8}$

The NAQ-R includes 22 items related to negative acts that result in bullying. Participants were asked to specify the frequency of occurrence of particular negative acts using a Likert scale, on which 1 indicated 'never', 2 'now and then', 3 'monthly', 4 'weekly' and 5 'daily'. The NAQ-R comprises three subscales associated with person-related bullying (12 items), work-related bullying (seven items) and intimidation-related bullying (three items). Additionally, the last question (question \#23) includes a self-labelled definition of bullying. Cronbach's alpha was previously reported to be 0.90 for the original version, and 0.94 for the Polish version. ${ }^{33}$ In our present study, Cronbach's alpha was 0.96 for the total scale, and $0.95,0.89$ and 0.68 for person-related, work-related and intimidation-related bullying, respectively.

We also developed a sociodemographic and workcharacteristic data sheet specifically for the present study. Table 1 presents all data from this sheet.

\section{Data analysis}

All of the data were analysed using IBM SPSS Statistics V.23. Descriptive statistics were used to assess sample characteristics. Categorical data was summarised using counts and percentages. For continuous variables the following descriptive statistics were used: mean, SD, median, range (min-max), skewness and kurtosis.

The Kolmogorov-Smirnov test and normal plots were used to check the normality of quantitative variable distribution. None of the analysed quantitative variables were found to be normally distributed. 
Table 1 Individual and work-related characteristics of the study participants $(n=404)$

\begin{tabular}{llrc}
\hline Factor & Description & $\mathbf{n}$ & $\begin{array}{l}\text { \% of total } \\
(\mathbf{n}=\mathbf{4 0 4})\end{array}$ \\
\hline Individual characteristics & & \\
Sex & Female & 389 & 96 \\
& Male & 15 & 4 \\
Age (years) & $<29$ & 75 & 18.6 \\
& $30-39$ & 92 & 22.8 \\
& $40-49$ & 134 & 33.2 \\
Educational & Nurse & 95 & 24 \\
level & Nurse +BA & 8 & 2 \\
& Nurse +MA & 42 & 10.4 \\
& Nurse +PhD & 123 & 30.4 \\
& Other & 5 & 55.4 \\
& Yes & 10 & 3 \\
\hline Postgraduate & No & 636 & 82.2 \\
education & No & &
\end{tabular}

\section{Work-related characteristics}

\begin{tabular}{|c|c|c|c|}
\hline \multirow{5}{*}{$\begin{array}{l}\text { Years working } \\
\text { in nursing }\end{array}$} & $<5$ & 75 & 18.6 \\
\hline & $6-10$ & 67 & 16.6 \\
\hline & $11-15$ & 44 & 10.9 \\
\hline & $15-20$ & 35 & 8.7 \\
\hline & $>20$ & 183 & 45.3 \\
\hline \multirow{8}{*}{$\begin{array}{l}\text { Current area of } \\
\text { work }\end{array}$} & General care ward & 101 & 25.0 \\
\hline & Surgical ward & 105 & 26.0 \\
\hline & $\begin{array}{l}\text { Long term/palliative } \\
\text { care }\end{array}$ & 17 & 4.2 \\
\hline & ER & 13 & 3.2 \\
\hline & ICU & 52 & 12.9 \\
\hline & Outpatient clinic & 60 & 14.9 \\
\hline & Other & 53 & 13.1 \\
\hline & Missing & 3 & 0.7 \\
\hline \multirow[t]{2}{*}{ Type of facility } & Public & 338 & 83.7 \\
\hline & Private & 66 & 16.3 \\
\hline \multirow{7}{*}{$\begin{array}{l}\text { Current } \\
\text { position }\end{array}$} & Director & 7 & 1.7 \\
\hline & Manager & 44 & 10.9 \\
\hline & Nurse coordinator & 26 & 8.9 \\
\hline & Clinical nurse & 300 & 74.3 \\
\hline & Epidemiology nurse & 7 & 1.7 \\
\hline & Scrub nurse & 1 & 0.2 \\
\hline & Other & 9 & 2.2 \\
\hline \multirow{3}{*}{$\begin{array}{l}\text { Working hours } \\
\text { per week }\end{array}$} & $<30$ & 17 & 4.2 \\
\hline & $30-45$ & 258 & 63.9 \\
\hline & $>45$ & 129 & 31.9 \\
\hline
\end{tabular}

BA, bachelor's degree; ER, Emergency; ICU, Intensive care unit; $\mathrm{MA}$, master's degree; $\mathrm{PhD}$, Doctor of Philosophy.
Spearman's rank correlation analysis was used to measure the strength and direction of association between two ranked variables (that is, to assess statistical dependence between the rankings of two not normally distributed quantitative variables). The differences between two groups of quantitative variables were compared using the non-parametric $U$ Mann-Whitney test. For comparison between more than two groups Kruskal-Wallis tests were used. The $\chi^{2}$ test was used to detect potential relationships between two categorical variables. Fisher's exact test was used when the $\chi^{2}$ test assumptions were not fulfilled.

Linear regression analysis was performed using a forward stepwise method to explain linear relationship between a bullying and all NAQ-R subscales and explanatory variables (sex, age, educational level, postgraduate education, years working in nursing, current area of work, type of facility, current position and working hours per week). Stepwise method has been used to include only such predictors in the model that significantly increase the fit of the model. Logistic regression analysis using the forward selection method was performed to explain the assignment of subjects to the category of victims or nonvictims. Variables significant in univariate analysis were selected as possible predictors for the regression model (years working in nursing, current area of work, current position and educational level). Variables on a nominal/ ordinal scale were recoded using a dummy coding procedure.

The classical threshold of $\mathrm{p} \leq 0.05$ was considered the level of significance.

\section{RESULTS}

\section{Participants' characteristics}

The survey was completed by 411 nurses, of whom 404 fulfilled the inclusion criteria. Therefore, the total study sample was 404 nurses. Table 1 summarises individual (sex, age, educational level, postgraduate education) and work-related (years working in nursing, current area of work, type of facility, current position and working hours per week) characteristics of the study population.

\section{Prevalence of workplace bullying}

Table 2 presents the NAQ-R results. The average mean NAQ-R score was $2.14(0.90)$. Bullying was experience by $65.84 \%$ of participants $(\mathrm{n}=266)$ according to Leymann's criterion, and by $51.73 \%$ of participants $(\mathrm{n}=209)$ according to Leymann's rigorous criterion. The mean score on questionnaire item \#23 ('Have you been bullied at work?') was 1.89 (0.99), with $46.78 \%$ of participants $(\mathrm{n}=189)$ responding that they had not been bullied at work during the past 6 months, $25.99 \%(\mathrm{n}=105)$ answering rarely, $19.06 \%(\mathrm{n}=77)$ answering 'now and then', $8.17 \%$ $(\mathrm{n}=33)$ answering several times per week and no participants stating that they had been bullied daily.

With regards to the subsections of the NAQ-R, workrelated bullying was the most common type of bullying: 2.31 (0.96), followed by person-related bullying: 2.13 
Table 2 Summary of descriptive analysis of bullying characteristics $(n=404)$. NAQ-R, Polish version.

\begin{tabular}{|c|c|c|}
\hline Section & Statement & $\begin{array}{l}\text { NAQ-R } \\
\text { score, M } \\
\text { (SD) }\end{array}$ \\
\hline \multirow{13}{*}{$\begin{array}{l}\text { Person- } \\
\text { related } \\
\text { bullying }\end{array}$} & Being the subject of excessive teasing and sarcasm & $2.96(1.22)$ \\
\hline & Spreading of gossip and rumours about you & $2.89(1.36)$ \\
\hline & Having your opinions ignored & $2.49(1.27)$ \\
\hline & Being shouted at or being the target of spontaneous anger & $2.45(1.24)$ \\
\hline & Being ignored or excluded & $2.42(1.40)$ \\
\hline & Excessive monitoring of your work & $2.32(1.34)$ \\
\hline & Being ignored or facing a hostile reaction when you approach & $2.24(1.30)$ \\
\hline & Persistent criticism of your errors or mistakes & $2.18(1.25)$ \\
\hline & Being humiliated or ridiculed in connection with your work & $2.17(1.26)$ \\
\hline & Having insulting or offensive remarks made about your person, attitudes, or your private life & $2.09(1.28)$ \\
\hline & Having allegations made against you & $2.08(1.15)$ \\
\hline & Repeated reminders of your errors or mistakes & $2.0(1.13)$ \\
\hline & Subtotal & $2.13(0.99)$ \\
\hline \multirow{6}{*}{$\begin{array}{l}\text { Work-related } \\
\text { bullying }\end{array}$} & Being ordered to do work below your level of competence & $2.74(1.40)$ \\
\hline & Being exposed to an unmanageable workload & $2.7(1.50)$ \\
\hline & Someone withholding information that affects your performance & $2.38(1.33)$ \\
\hline & Having key areas of responsibility removed or replaced with more trivial or unpleasant tasks & $2.35(1.32)$ \\
\hline & Being given tasks with unreasonable deadlines & $1.73(1.07)$ \\
\hline & Subtotal & $2.31(0.96)$ \\
\hline \multirow{6}{*}{$\begin{array}{l}\text { Intimidation- } \\
\text { related } \\
\text { bullying }\end{array}$} & $\begin{array}{l}\text { Pressure not to claim something to which by right you are entitled (eg, sick leave, holiday } \\
\text { entitlement, travel expenses) }\end{array}$ & $2.05(1.17)$ \\
\hline & Hints or signals from others that you should quit your job & $1.71(1.09)$ \\
\hline & $\begin{array}{l}\text { Intimidating behaviours such as finger-pointing, related invasion of personal space, shoving, or } \\
\text { blocking your way }\end{array}$ & $1.55(1)$ \\
\hline & Practical jokes carried out by people you don't get along with & $1.44(0.89)$ \\
\hline & Threats of violence or physical abuse or actual abuse & $1.17(0.61)$ \\
\hline & Subtotal & $1.72(0.77)$ \\
\hline
\end{tabular}

M, Mean; NAQ-R, Negative Acts Questionnaire-Revised.

(0.99) and then intimidation-related bullying: 1.72 (0.77). The lowest mean score was for the item 'threats of violence or physical abuse or actual abuse': $1.17(0.61)$, followed by 'practical jokes carried out by people you don't get along with': 1.44 (1.27) and then by 'intimidating behaviours such as finger-pointing, related invasion of personal space, shoving, blocking your way': 1.55 (1). The highest mean score was for the item 'spreading of gossip and rumours about you': 2.89 (1.36), followed by 'being ordered to do work below your level of competence': 2.74 (1.40) and then by 'being exposed to an unmanageable workload': 2.7 (1.50). The mean results for all items of NAQ-R and subscales are presented in table 2.

\section{Relationship between bullying and socio-demographic variables}

The mean score for work-related bullying significantly differed $(\mathrm{p}=0.043)$ between male and female participants.
Compared with men, women were more often affected by 'being humiliated or ridiculed in connection with your work' $(p=0.040)$, 'being ordered to do work below your level of competence' $(\mathrm{p}=0.010)$, and 'having key areas of responsibility removed or replaced with more trivial or unpleasant tasks' $(\mathrm{p}=0.005)$.

The nurse's age showed a weak negative correlation with work-related bullying $(\mathrm{r}=-0.128, \mathrm{p}=0.010)$, personrelated bullying $(\mathrm{r}=-0.128, \mathrm{p}=0.010)$ and bullying assessed by Leymann's criteria $(\mathrm{r}=-0.145, \mathrm{p}=0.003)$. The correlation between age and perception of bullying was confirmed by the $\chi^{2}$ test: $\chi^{2}(4)=11.05, p=0.026, V=0.17$.

Seniority showed weak negative correlations with bullying $(\mathrm{r}=-0.136, \mathrm{p}=0.006)$ and with two NAQ-R subscales: work-related bullying $(r=-0.122, p=0.014)$ and person-related bullying $(\mathrm{r}=-0.116, \mathrm{p}=0.020)$. The $\chi^{2}$ test also confirmed that there was a higher number of bullying 
victims among nurses with less seniority: $\chi^{2}(4)=12.72$, $\mathrm{p}=0.013, V=0.18$.

The number of working hours per week was correlated with work-related bullying $(\mathrm{r}=0.132, \mathrm{p}=0.008)$, personrelated bullying $(r=0.121, p=0.015)$, subjective bullying assessment $(\mathrm{r}=0.111, \mathrm{p}=0.026)$, and bullying assessment by Leyman's criteria $(\mathrm{r}=0.129, \mathrm{p}=0.010)$. The $\chi^{2}$ test confirmed the correlation between the number of working hours per week and the perception of bullying: $\chi^{2}(2)=6.27, p=0.043, V=0.13$.

Our analyses revealed that education level, work facility (public or private), and unit characteristics had no significantly significant association with participants' scores on the NAQ-R or on the NAQ-R subscales.

For the next step, we checked whether the level of bullying differed depending on the work position. A series of analyses performed using the Kruskal-Wallis test revealed that position was significantly related to workrelated bullying $(\mathrm{H}(6)=14.02 ; \mathrm{p}=0.029)$ and subjectively assessed bullying $(\mathrm{H}(6)=16.98 ; \mathrm{p}=0.009)$. A separate post-hoc analysis using the Dunn-Sidak test revealed that nursing managers experienced a significantly lower level of bullying compared with clinical nurses $(p=0.003)$, coordinating nurses $(p=0.029)$, other nurses $(p=0.002)$ and scrub nurse $(\mathrm{p}=0.033)$. We then analysed these differences relative to the dimension of work-related bullying. The lowest results on the subscales were also recorded from nursing managers, which significantly differed from the subscale scores of coordinating nurses $(p=0.046)$, clinical nurses $(\mathrm{p}=0.004)$ and other nurses $(\mathrm{p}=0.006)$

\section{Regression model}

The strongest association was revealed in logistic regression analysis, where the dependent variable was classification as a bullying victim according to Leymann's criteria, and independent variables included seniority of 11-15 years, seniority of $>20$ years, and over 45 working hours per week. Greater seniority was associated with a lower chance of becoming a bullying victim, while more working hours per week was associated with a greater risk of being a bullying victim. The power of explanation of the model was described by a Nagelkerke's $R^{2}$ value of 0.071 .

We also performed logistic regression analysis in which the dependent variable was classification as a bullying victim by Leymann's rigorous criteria, and four independent variables: age from 50 to 59 , seniority of 11-15 years, $>45$ working hours per week, and a bachelor's degree in nursing. The first two variables (age of 50-59 and seniority of 11-15 years) reduced the risk of bullying, while the other two variables ( $>45$ working hours per week and bachelor's degree in nursing) increased the risk of bullying. The power of explanation of the model was described by a Nagelkerke's $\mathrm{R}^{2}$ value of 0.085 . Table 3 presents the results of the regression analyses in relation to both Leymann's criteria and Leyamnn's rigorous criteria as dependent variable.

In order to summarise results, it should be stated that bullying among Polish nurses is a serious problem. This study has confirmed hypothesis that sociodemographic variables are related with bullying. Variables most closely correlated with bullying are age, seniority, work overtime and bachelor's degree education.

\section{DISCUSSION}

In our current study, we found a prevalence of bullying among Polish nurses in 2018 that was similar to the results of comparable studies in European countries. Among the presently surveyed nurses, about half were victims of bullying. Interestingly, none reported an experience of daily bullying based on the given definition. Other European studies of workplace bullying among nurses

Table 3 Regression analysis.

Values of logistic regression coefficients predicting belonging to a group of bullying victims or a group of non-victims according to Leymann's criteria

\begin{tabular}{llllrrl}
\hline & B & SE & Wald & P value & Exp(B) \\
\hline Step 3 & Seniority of 11-15 years & 0.98 & 0.35 & 7.63 & 0.006 & 2.66 \\
& Seniority of $>$ 20 years & 0.80 & 0.24 & 11.73 & 0.001 & 2.23 \\
& $>$ 45 working hours per week & -0.69 & 0.24 & 8.10 & 0.004 & 0.50 \\
& Constant & -0.14 & 0.41 & 0.12 & 0.726 & 0.87 \\
\hline
\end{tabular}

Values of logistic regression coefficients predicting belonging to a group of bullying victims or a group of non-victims according to Leymann's rigorous criteria

\begin{tabular}{llrlrrl}
\hline & \multicolumn{1}{c}{$\boldsymbol{B}$} & SE & Wald & P value & Exp(B) \\
\hline Step 4 & Age of 50-59 years old & 0.89 & 0.25 & 12.49 & $<0.001$ & 2.42 \\
& Bachelor's degree in nursing & -0.48 & 0.23 & 4.43 & 0.035 & 0.62 \\
& Seniority of 11-15 years & 0.92 & 0.34 & 7.20 & 0.007 & 2.50 \\
& $>$ 45 working hours per week & -0.58 & 0.23 & 6.60 & 0.01 & 0.56 \\
& Constant & -0.70 & 0.44 & 2.49 & 0.114 & 0.50 \\
\hline
\end{tabular}

B- Non-standardized Standardized; FactorExp(B)- odds ratios for the predictors. 
have revealed prevalence rates ranging from $9 \%$ among Danish nurses in their first year after graduation ${ }^{34}$ to over $74 \% .{ }^{35}$ The rate of bullying reported in our present study was substantially higher than the $18.6 \%$ rate reported in another study of Polish nurses using the NAQ-R ${ }^{36}$ This inconsistency may be due to the differences in research methodology. In our study, data were collected using an online survey. Young nurses feel more comfortable using new technology in daily practice, and the majority of our study participants were younger compared with the mean age of Polish nurses, which is about 51 years. ${ }^{37}$ The use of an electronic survey enabling participation in the study in a place and time convenient for the participant was selected due to the subject of the study and possible bias in collecting data resulting from the place associated with the employer. Both correlation and regression analyses showed that age influenced the experience of bullying, with the oldest group of nurses surveyed being the least likely to experience bullying. This relationship may have influenced our results; however, our findings were similar to those previously presented by other authors. ${ }^{162324}$

Compared with female nurses, the male nurses in our study reported experiencing significantly less workrelated bullying; however, the number of men in this study was significantly smaller than the number of women. This finding differs from previously reported results. Giorgi et al revealed no correlation between these variables. ${ }^{12}$ Other prior studies have reported higher exposure to bullying among men than women. ${ }^{19}{ }^{23}$ The discrepancy may be explained by socio-cultural tradition, as well as by the fact that men remain the minority among nursing professionals in Poland, ${ }^{37}$ which might result in better and more adequate utilisation of their potential.

One variable that significantly correlated with the occurrence of bullying in this study was seniority, in that the nurses with the least seniority were more likely to experience workplace bullying. Similar results have been presented by other authors. ${ }^{16}{ }^{24}$ Unhealthy work environments, including bullying behaviours, cause stress ${ }^{21} 35$ and increase the intention to leave the profession among young nurses. ${ }^{538}$ Laschinger et al highlight that new nurse recruitment and retention has become a high priority for healthcare systems worldwide, within the context of the current nursing shortage and ageing workforce. ${ }^{38}$ Current information regarding the mean age of nurses in Poland and the poor substitutability of young employees for retiring nurses ${ }^{37}$ supports the importance of focusing on creating healthy work environment for novice nurses.

Our present data also showed that nurses with a bachelor's degree were exposed to bullying more than nurses with other educational levels. Obligatory nursing education at the academic level was introduced in Poland starting in 2000, in accordance with the Bologna Declaration. Therefore, the youngest nurses have at least a bachelor's degree in nursing, and they start their professional career with this title. Studies by Yokoyama et al and Karatza et al have confirmed that education level influences the risk of negative acts in the workplace. ${ }^{1625}$ Our qualitative analyses showed that having to work below one's level of competence was the most common form of work-related bullying experienced, and the majority of surveyed nurses presented high qualifications. These findings suggest that managers should consider how to better organise the nursing workplace and to better use professional competences. Such changes could have positive effects on organisational outcomes and patient care, as well as benefits for the nurses, who may experience increased job satisfaction and professional well-being and consequently decreased intent to leave the profession.

Nurses working more hours per week reported higher exposure to workplace bullying, which was in line with the findings of Oh et al and Yang et al. ${ }^{27}{ }^{39}$ We found that working overtime ( $>41$ hours per week) was a predictor of workplace bullying overall and on the subscales of personal and work-related bullying. Unfortunately, studies of nursing have previously reported unmanageable workloads. ${ }^{13}$ Longer working hours often mean work overload, which could increase one's sensitivity to bullying perception, as well as increase the possible exposure to violence. It may be important for nursing managers to increase the transparency of workload division, and to consider workload predictability as much as possible during allocation. Our findings suggest that when attempting to decrease workplace bullying, organisation leaders should consider appropriate staffing levels which has become particularly difficult in the last decade, after 2007-2008, when the economic crisis began. At that time, changes in work environments were observed, such as increased workload, staff shortage, what had negative impact on working conditions and health of people. ${ }^{40-42}$ Moreover, studies taking into account the context of the nursing environment indicate the importance of the perceptions of the economic crisis on the development of burnout and engagement. ${ }^{43}$ It is worth noting that the relationship between these factors and the occurrence of bullying illustrates the complexity of the problem and the need for careful monitoring in the context of many variables.

The occurrence of bullying also depended on the nurse's professional position. Compared with other surveyed nurses, nursing managers reported a lower level of bullying, particularly in terms of work-related bullying. Notably, earlier analyses show that managers are the main perpetrators of bullying, both in Poland ${ }^{36}$ and in other countries. ${ }^{6} 1323$ In daily practice, nurse managers should build up a healthy work environment that demonstrates respect and fairness. There is a need for training nurse managers to develop skills and abilities that favour relationships with their subordinates in order to prevent bullying and turnover intention among nurses. ${ }^{14}$ However, until organisations start monitoring the direct supervision and organisation of nurses' work with regards to bullying, it will be difficult to combat this phenomenon. Organisational policies should strongly prohibit negative acts and implement immediate remedial actions. Importantly, previous studies show that bullying affects patients' outcomes and medical errors 
and leads to a decreased quality of life for nurses, and reduced ability to deliver effective and safe patient care $^{17-19}$; therefore, actions to prevent bullying are necessary to improve healthcare system functioning. However, for those nurses who are not perpetrators but a victim, it is important to cope with the aggression experienced. Yu et al revealed that increased nurse resilience can help nurses reduce the effects of stress, reduce emotional exhaustion and enhance function when facing workplace challenges. ${ }^{44}$ As both a personal coping measure for person-related and work-related bullying among nurses and decreasing turnover intention, Kang et al recommended the smartphone application-based cognitive rehearsal intervention. ${ }^{15}$ Resolving workplace bullying within the nursing profession requires a comprehensive approach that accounts for individual and organisational factors. ${ }^{45}$

The present results support several useful suggestions for taking action to develop a healthier work environment. Directors of healthcare facilities are encouraged to introduce more measures for bullying prevention on the individual, unit and institutional levels.

It is important to recognise the group of employees with the highest risk of exposure to workplace bullying, and then to take actions to reduce the sources of stress. Our recommendation for directors is to attempt to monitor young nurses during their adaptation and to develop mentoring programme. Managers who play crucial roles in this process should be supervised and externally supported. Moreover, workers should be given increased resources to deal with stressors. Nurses at all levels-including nursing students, managers and staff nurses-should be educated to have zero tolerance of bullying and to report bullying anytime.

\section{Limitations of the study}

This study was quantitative and cross-sectional, and designed to assess negative acts in the nursing workplace within a given time frame. However, such behaviours may change over time and differ among workplaces, limiting the generalisability of this study's findings to other times and places. The investigated nurse population was recruited via the Internet, and thus we could not determine the response rate. Although a CBOS (Public Opinion Research Centre) report shows that the majority of Poles use the Internet, ${ }^{46}$ it is possible that older nurses may have limited access to new technologies, including the Internet. This might explain why the characteristics of the target research group were slightly different from the average. The surveyed nurses included only one scrub nurse, who presented extremely high scores in the context of the experience of bullying. Therefore, attempts to generalise our study results to operating theatre nurses should be approached with caution. Future studies should include investigation specifically focused on this group of nurses to examine the workplace bullying level within this group of professionals.

\section{CONCLUSIONS}

In conclusion, our present study revealed that an alarmingly high percentage of Polish nurses were victims of bullying. Among the variables included in the regression model, the most significant predictors of perceived workplace bullying were age, seniority, work overtime and bachelor's degree education. These findings suggest that developing and improving nurses' adaptation mentoring programme may help to reduce the prevalence of workplace bullying among nurses. Bullying prevention and improvement of well-being at work must be addressed as part of an overall strategy to deal with turnover. Organisations policies should declare zero tolerance for workplace violence and completely eliminate any 'eating the young' culture.

Acknowledgements The researchers are grateful to the Warsaw District Chamber of Nurses and Midwives.

Contributors Made substantial contributions to conception and design, or acquisition of data, or analysis and interpretation of data; Involved in drafting the manuscript or revising it critically for important intellectual content; Given final approval of the version to be published (LIS, BC-P). Each author should have participated sufficiently in the work to take public responsibility for appropriate portions of the content; Agreed to be accountable for all aspects of the work in ensuring that questions related to the accuracy or integrity of any part of the work are appropriately investigated and resolved (LIS, BC-P).

Funding The authors have not declared a specific grant for this research from any funding agency in the public, commercial or not-for-profit sectors.

Competing interests None declared.

Patient consent for publication Not required.

Ethics approval The study was positively assessed by the Ethical Board at the Medical University of Warsaw (reference number AKBE/117/2018).

Provenance and peer review Not commissioned; externally peer reviewed. Data availability statement No data are available.

Open access This is an open access article distributed in accordance with the Creative Commons Attribution Non Commercial (CC BY-NC 4.0) license, which permits others to distribute, remix, adapt, build upon this work non-commercially, and license their derivative works on different terms, provided the original work is properly cited, appropriate credit is given, any changes made indicated, and the use is non-commercial. See: http://creativecommons.org/licenses/by-nc/4.0/.

ORCID iD

Lena Izabela Serafin http://orcid.org/0000-0003-1364-5767

\section{REFERENCES}

1 International Center of Nurse Migration. Policy brief: nurse retention, 2018. Available: https://www.icn.ch/sites/default/files/inline-files/ 2018_ICNM\%20Nurse\%20retention.pdf [Accessed 20 Feb 2019].

2 International Council of Nurses. Icn international workforce forum calls for urgent action from governments to address global nursing shortage, 2019. Available: https://www.icn.ch/news/icn-internationalworkforce-forum-calls-urgent-action-governments-address-globalnursing [Accessed 20 Feb 2019].

3 World Health Organization. Global strategy on human resources for health: workforce 2030, 2016. Available: http://www.who.int/hrh/ resources/16059_Global_strategyWorkforce2030.pdf?ua=1\&ua=1 [Accessed 15 Feb 2019].

4 de Oliveira DR, Griep RH, Portela LF, et al. Intention to leave profession, psychosocial environment and self-rated health among registered nurses from large hospitals in Brazil: a cross-sectional study. BMC Health Serv Res 2017;17:1-10.

5 Rudman A, Gustavsson P, Hultell D. A prospective study of nurses' intentions to leave the profession during their first five years of practice in Sweden. Int J Nurs Stud 2014;51:612-24. 
6 AL-Sagarat A, Qan'ir Y, AL-Azzam M, et al. Assessing the impact of workplace bullying on nursing competences among registered nurses in Jordanian public hospitals. Nurs Forum 2018;53:304-13.

7 Leymann $\mathrm{H}$. Mobbing and psychological terror at workplaces. Violence Vict 1990;5:119-26.

8 Einarsen S, Hoel H, Notelaers G. Measuring exposure to bullying and harassment at work: validity, factor structure and psychometric properties of the negative acts Questionnaire-Revised. Work Stress 2009;23:24-44.

9 Einarsen S, Hoel H, Zapf D. The concept of bullying and harassment at work: The European tradition. In: Einarsen S, Hoel H, Zapf D, eds. Bullying and harassment in the workplace. New York: Taylor\&Francis, 2011: 3-39.

10 Mikkelsen EG, Einarsen S. Bullying in Danish work-life: prevalence and health correlates. Eur J Work Organ. Psychol 2001:10:393-413.

11 Laschinger HKS. Job and career satisfaction and turnover intentions of newly graduated nurses. J Nurs Manag 2012;20:472-84.

12 Giorgi G, Mancuso S, Fiz Perez F, et al. Bullying among nurses and its relationship with burnout and organizational climate. Int $J$ Nurs Pract 2016;22:160-8.

13 Johnson SL, Rea RE. Workplace bullying: concerns for nurse leaders. J Nurs Adm 2009;39:84-90.

14 Fontes KB, Alarcão ACJ, Santana RG, et al. Relationship between leadership, bullying in the workplace and turnover intention among nurses. J Nurs Manag 2019;27:535-42 https://doi.org/

15 Kang J, Jeong YJ. Effects of a smartphone application for cognitive rehearsal intervention on workplace bullying and turnover intention among nurses. Int J Nurs Pract 2019;15:e12786.

16 Yokoyama M, Suzuki M, Takai Y, et al. Workplace bullying among nurses and their related factors in Japan: a cross-sectional survey. $J$ Clin Nurs 2016;25:2478-88.

17 Sauer PA, McCoy TP. Nurse bullying: impact on nurses' health. West J Nurs Res 2017;39:1533-46.

18 Roche M, Diers D, Duffield C, et al. Violence toward nurses, the work environment, and patient outcomes. J Nurs Scholarsh 2010;42:13-22.

19 Wright W, Khatri N. Bullying among nursing staff: relationship with psychological/behavioral responses of nurses and medical errors. Health Care Manage Rev 2015;40:139-47.

20 Arcangeli G, Giorgi G, Ferrero C, et al. [Prevalence of workplace bullying in a population of nurses at three Italian hospitals]. $G$ Ital Med Lav Ergon 2014:36:181-5.

21 Spence Laschinger HK, Nosko A. Exposure to workplace bullying and post-traumatic stress disorder symptomology: the role of protective psychological resources. J Nurs Manag 2015;23:252-62 https://doi.org/

22 Matthiesen SB, Einarsen S. Psychiatric distress and symptoms of PTSD among victims of bullying at work. Br J Guid Counc 2004;32:335-56.

23 Obeidat RF, Qan'ir Y, Turaani H. The relationship between perceived competence and perceived workplace bullying among registered nurses: a cross sectional survey. Int J Nurs Stud 2018;88:71-8.

24 Vessey JA, DeMarco RF, Bullying DR. Harassment and horizontal violence in the nursing workforce. Annu Rev Nurs Res 2010;28:133-57.

25 Ch K, Zyga S, Tziaferi S, et al. Workplace bullying and general health status among the nursing staff of Greek public hospitals. Ann Gen Psychiatry 2016;15:3.

26 Ganz FD, Levy H, Khalaila R, et al. Bullying and its prevention among intensive care nurses. J Nurs Scholarsh 2015;47:505-11.
27 Oh H, Uhm DC, Yoon YJ. Factors affecting workplace bullying and lateral violence among clinical nurses in Korea: descriptive study. $J$ Nurs Manag 2016;24:327-35.

28 Vogelpohl DA, Rice SK, Edwards ME, et al. New graduate nurses perception of the workplace: have they experienced bullying? J Prof Nurs 2013;29:414-22.

29 Spector PE, Zhou ZE, Che XX. Nurse exposure to physical and nonphysical violence, bullying, and sexual harassment: a quantitative review. Int J Nurs Stud 2014;51:72-84.

30 Szutenbach MP. Bullying in nursing: roots, rationales, and remedies. J Christ Nurs 2013;30:16-23.

31 Gove S, Burns N, Gray J. Practice of nursing research. Saint Louis: Elsevier, 2013: 367.

32 Einarsen S, Hoel H. The Negative Acts Questionnaire: Development, validation and revision of a measure of bullying at work. Paper presented at the 9th European Congress on Work and Organisational Psychology: Globalisation-Opportunities and Threats, Prague, 2001.

33 Warszewska-Makuch M. Polska adaptacja kwestionariusza NAQ do pomiaru mobbingu. Bezpieczeństwo pracy 2007;12:16-19.

34 Hogh A, Hoel H, Carneiro IG. Bullying and employee turnover among healthcare workers: a three-wave prospective study. J Nurs Manag 2011;19:742-51.

35 Topa G, Moriano JA. Stress and nurses' horizontal mobbing: Moderating effects of group identity and group support. Nurs Outlook 2013;61:e25-31.

36 Kunecka D. Skala zjawiska mobbingu wśród pielęgniarek/pielęgniarzy zatrudnionych W szczecińskich szpitalach. Medycyna Pracy 2008;59:223-8.

37 Main Chamber of Nurses and Midwives. Raport Naczelnej Izby Pielęgniarek i Położnych. Zabezpieczenie Społeczeństwa Polskiego W świadczenia pielęgniarek I położnych, 2017. Available: https:// nipip.pl/wp-content/uploads/2017/03/Raport_druk_2017.pdf [Accessed 19 Feb 2019].

38 Laschinger HKS, Grau AL, Finegan J, et al. New graduate nurses' experiences of bullying and burnout in hospital settings. J Adv Nurs 2010;66:2732-42.

39 Yang L-Q, Spector PE, Chang C-HD, et al. Psychosocial precursors and physical consequences of workplace violence towards nurses: a longitudinal examination with naturally occurring groups in hospital settings. Int J Nurs Stud 2012;49:1091-102.

40 Buchan J, O'May F, Dussault G. Nursing workforce policy and the economic crisis: a global overview. J Nurs Scholarsh 2013;45:298-307.

41 Mucci N, Giorgi G, Roncaioli M, et al. The correlation between stress and economic crisis: a systematic review. Neuropsychiatr Dis Treat 2016;12:983-93

42 Megaritis C, Sakellari E, Psychogiou M, et al. Exploring home care nurses' perceptions regarding their services in economic crisis: A qualitative approach. Nurs Forum 2018:53:521-8 https://doi.org/

43 Manzano-García G, Montañés P, Megías JL. Perception of economic crisis among Spanish nursing students: its relation to burnout and engagement. Nurse Educ Today 2017;52:116-20.

44 Yu F, Raphael D, Mackay L, et al. Personal and work-related factors associated with nurse resilience: a systematic review. Int J Nurs Stud 2019:93:129-40.

45 Yun S, Kang J. Influencing factors and consequences of workplace bullying among nurses: a structural equation modeling. Asian Nurs Res 2018;12:26-33.

46 Public Opinion Research Center. Korzystanie Z Internetu, 2017. 